\title{
A IMPORTANCIA DO OUTDOOR PARA O PODER PÚBLICO
}

\author{
Valéria de Camargo Amoris*
}

RESUMO

O objetivo central do estudo consiste em mostrar a importância do outdoor como meio de comunicação de massa, discutir a sua exposição no espaço físico, na paisagem urbana de diferentes cidades brasileiras, além de verificar como os prefeitos vêm fazendo campanha eleitoral por meio dessa mídia. Discute-se, também, como os anúncios realizados pelas prefeituras, de um modo geral, alteraram o conceito da comunicação pública. Para isso, utilizaremos um recorte temporal dos outdoors,escolhidos de forma aleatória,nas cidades mineiras de Congonhas e Varginha; na Estância de Atibaia, interior de São Paulo; no município de Nova Mutum, no Mato Grosso; das cidades de Vitória da Conquista, São Sebastião do Passé e Mucuri, na Bahia; em Cariacica, no Espírito Santo e na capital do Sergipe, Aracaju. Pretende-se fornecer subsídios teóricos para uma reflexão sobre o fato de como as organizações municipais utilizam a comunicação de massa para alterar o conceito de comunicação pública.Trata-se, portanto de uma pesquisa bibliográfica, voltada sobretudo à comunicação pública e à comunicação política que se utilizam do outdoor como exemplo dessa manifestação.

Palavras-chave: comunicação pública; cidadania; outdoors; meio de comunicação de massa.

Valéria de Camargo Amoris é jornalista, mestre em Comunicação Política pela USCS e doutoranda em Comunicação Social pela Universidade Metodista, de São Paulo - UMESP.

valeria-amoris@uol.com.br 


\section{INTRODUCÃO}

A partir de uma perspectiva crítica, é possível visualizar a comunicação sob múltiplos fatores: sociais, econômicos, políticos e culturais.Desse modo, busca-se compreender as transformações comunicacionais que norteiam a sociedade contemporânea.

Nessa direção, faz-se necessário considerar as influências exercidas sobre a elaboração normativa do sistema político e ideológico dominante na sociedade comouma reconstrução constante da ciência, a partir da movimentação histórica da sociedade e de um espaço onde o oculto é capaz de aparecer e assumir sua existência.

Resgatamos, assim, a questão de "mudar conceitos". Talvez na época das eleições municipais, os indivíduos esperem uma quebra de paradigmas. Por que não? Infelizmente, nossa realidade encontra-se longe de mudanças. Quando nos deparamos com os anúncios realizados pelas prefeituras, de um modo geral, notamos que o objetivo da comunicação pública se encontra totalmente distorcido.

Isso nos leva a pensar que a comunicação, que deveria atualizar o cidadão e propiciar sua participação, acaba usada como discurso de consumo, de publicidade. Ou seja, altera-se o objetivo da comunicação: ela, que deveria integrar o cidadão, é usada para buscar votos e a adesão aos partidos.

Justamente a partir dessa perspectiva, entendemos que a comunicação sempre foi importante para todos os setores, principalmente para a área pública. Um dos aspectos que vem chamando a atenção encontra-se no modo como a comunicação impacta os governos municipais, estaduais e federais. Essa influência vem ocorrendo, em grande parte, devido à implantação da democracia.

$\mathrm{Na}$ realidade, a liberdade de expressão, o direito de interagir junto à esfera pública, o conhecimento sobre as ações dos governos aumentaram em virtude da atual concepção adquirida a partir das características do novo modelo de sociedade que vivenciamos.

Nesta nova era, norteada pela informação, que nos chega em velocidade imensurável, o processo de comunicar-se tornou-se tão valioso quanto o ar que respiramos. Em meio a tantas transformações, a comunicação conquistou espaço, importância e múltiplos entendimentos e funções. Assim, voltamos nossa atenção às estratégias de campanha das prefeituras.

O objetivo central do estudo consiste emmostrar a importância do outdoor como meio de comunicação de massa, discutir a sua exposição no espaço físico, na paisagem urbana de diferentes cidades brasileiras e verificar como os prefeitos, de um modo geral, vêm fazendo as campanhas eleitorais por meio dessa mídia. Discute-se, a partir de subsídios teóricos, como os anúncios realizados pelas prefeituras alteraram o conceito da comunicação pública. 
Antes de mais nada, há que se esclarecer o conceito de comunicação pública,diferente de comunicação governamental e de comunicação política. De maneira sucinta, entendemos que a comunicação governamental é praticada por um determinado governo, visa à prestação de contas, ao engajamento da população nas políticas adotadas e ao reconhecimento das ações promovidas nos campos político, econômico e social. Constitui uma forma legítima de o governo fazer-se presente junto à população.

Já a comunicação política, mais conhecida como marketing político, consiste em uma maneira de divulgar um político, ou um partido político, focando o processo eleitoral, dependendo, assim, da insubstituível legitimação da sociedade.

Tanto a comunicação governamental, quanto a política têm o objetivo de atingir a opinião pública, já que, na maioria das vezes, fazem uso da propaganda, ou da campanha publicitária, nas quais buscam respostas rápidas e efeitos imediatos por meio de pesquisas de opinião, de que se possam construir futuras estratégias de campanha. Essa é uma pratica muito usual e comum entre os políticos e seus partidos.

Já a comunicação pública implica uma prática comprometida com a democracia e a construção da cidadania, o que supõe um posicionamento político(que não é o mesmo que partidário). Viabiliza o direito social coletivo e individual ao diálogo, à informação e à expressão. Assim, fazer comunicação pública é assumir a perspectiva cidadã na comunicação, a partir detém as de interesse coletivo.

Este trabalho constitui, portanto, uma pesquisa bibliográfica, voltada, sobretudo, à comunicação pública e à comunicação política que se utilizam do outdoor.

Observamos como, por meio deles, os administradores municipais realizam campanha eleitoral. Pretende-se, nessa direção, destacar a importância da propaganda eleitoral nos outdoors, tendo em vista que ela constitui um meio de informação, uma vez que, por intermédio dela,o cidadão toma conhecimento das benfeitorias, trazidas pelo prefeito,e também do desenvolvimento das obras de governo.

Nessa pesquisa bibliográfica com caráter qualitativo, utilizaremos o recorte temporal dos outdoors, escolhidos de forma aleatória nas cidades mineiras de Congonhas e Varginha; na Estância de Atibaia, interior de São Paulo;no município de Nova Mutum, no Mato Grosso;nas cidades de Vitória da Conquista, São Sebastião do Passé e Mucuri, todas na Bahia; em Cariacica, no Espírito Santo e na capital do Sergipe, Aracaju. 


\section{PESQUISA BIBLIOGRÁFICA}

Optamos por esse método pois, num sentido amplo, abarca desde a identificação, a localização e a obtenção da bibliografia pertinente sobre o assunto, até a apresentação de um texto sintetizado. Atentamo-nos às observações de Ida Regina C. Stumpf (2009, p.51) sobre a pesquisa bibliográfica constituir um conjunto de procedimentos para identificar, selecionar, localizar e obter documentos de interesse. Além disso, de acordo com a autora, quando o pensamento e as descobertas passaram a ser registrados, o Homem não precisou mais valer-se apenas de sua memória biológica para lembrar dos fatos e dos acontecimentos. A tradição oral deu lugar aos registros impressos e estes, pela capacidade de preservação do saber, permitiram a transmissão do conhecimento com mais precisão. As tecnologias de impressão possibilitaram a duplicação em maior escala e a ampliação do alcance geográfico do saber.

$\mathrm{Na}$ intenção de apresentar a pesquisa bibliográfica sob essa perspectiva, o presente artigo aborda a importância de delimitar os critérios e os procedimentos metodológicos que permitem definir um estudo com o bibliográfico. Através de exemplos, construídos a partir de uma pesquisa dessa natureza, pretende-se chamar a atenção para as exigências que a escolha por esse tipo de procedimento apresenta ao pesquisador, à medida que este constrói a busca por soluções ao objeto de estudo proposto.

Entende-se pesquisa como um processo no qual o pesquisador assume "uma atitude e uma prática teórica de constante busca, que define um processo intrinsecamente inacabado e permanente". Isso porque realiza uma atividade de aproximações sucessivas à realidade, que apresenta "uma carga histórica" e reflete posições frente à realidade (MINAYO, 1994, p.23). Desse modo, ao considerar a pesquisa qualitativa, todo objeto de estudo possui especificidades, pois ele:

a) apresenta natureza histórica - localiza-se temporalmente, podendo sofrer transformações;

b) possui consciência histórica - não é apenas o pesquisador que lhe atribui sentido, mas a totalidade dos Homens, na medida em que se relaciona em sociedade e confere significados e intencionalidades a suas ações e construções teóricas;

c) apresenta uma identidade com o sujeito - ao propor investigar as relações humanas, de uma maneira ou de outra, o pesquisador identifica-se com ele;

d) intrínseca e extrinsecamente ideológico porque "veicula interesses e visões de mundo historicamente construídas e se submete e resiste aos limites dados pelos esquemas de dominação vigentes" (MINAYO, 1994, p. 21). 


\section{REALIDADE ESTUDADA}

Interessante pensar no processo que transforma os outdoors, utilizados pelas prefeituras, aparentemente, para apenas comunicar seus projetos efeitos, em grande propaganda do partido no poder, principalmente, em ano eleitoral.

De origem inglesa, a palavra outdoor significa "do lado de fora da porta". Publicitariamente, constitui a abreviatura da expressão outdoor advertising, que significa "propaganda ao ar livre".Justamente esse tipo de propaganda adquiriu grande impacto, visto que, nele, o produto fica muito tempo em evidência. Por isso, sempre que um produto, ou serviço, necessita ser anunciado de forma decisiva, o outdoor é um dos meios mais lembrados.

Instalado no perímetro urbano das capitais e dos principais municípios brasileiros, o outdoor dirige sua mensagem, basicamente, à população das cidades. Podemos dizer que, porque ele exibe uma mensagem 24 horas por dia,constitui um dos meios que mais expõe, quantitativamente, o produto, ou o serviço. Presente nas ruas, nas praças e nas avenidas, o outdoor é veículo cuja mensagem não pode agredir, de forma alguma, os diversos públicos-alvo a que se direciona.

Muitas vezes, essa mídia caiu nas graças do poder público, e não de agora. Na década de 1970, por exemplo, a veiculação da propaganda ao ar livre foi proibida por motivos políticos, devido à ditadura militar. Eram raros os outdoors nas ruas e os que se viam transmitiam mensagens do governo, como, em 1968, nas ruas do Rio de Janeiro:para dar as boas-vindas à Rainha da Inglaterra, Elizabeth II, foram instaladas tabuletas pelo percurso que ela iria fazer,desde o aeroporto até o hotel onde se hospedaria. Utilizava-se o outdoor, ainda, para esconder as favelas existentes e outras realidades visualmente desagradáveis do panorama brasileiro.

Sabadin (1990, p. 83) afirma:

(...) outdoor é mídia por natureza. Enquanto nos demais veículos de comunicação, a propaganda é um suporte financeiro inserido em um contexto editorial, no outdoor ela é tudo - razão de existência do próprio meio. Uma emissora de rádio ou TV, um jornal, uma revista ou um cinema podem sobreviver sem publicidade. O outdoor não; ele é a própria propaganda em si. E com uma característica muito particular: ele "mistura bem" com todos os demais veículos publicitários, gerando sempre um mix de comunicação bastante eficiente (Celso SABADIN, p. 83).

Esse veículo urbano, com grandioso poder de comunicação,permite que os anúncios dos governos (municipais, estaduais e federal) adquiram imensa visibilidade. Por isso, a administração pública utiliza para veicular campanhas de cunho social e de interesse comunitário. 
Podemos observar alguns exemplos de outdoors, como os da cidade de Congonhas, em Minas Gerais:

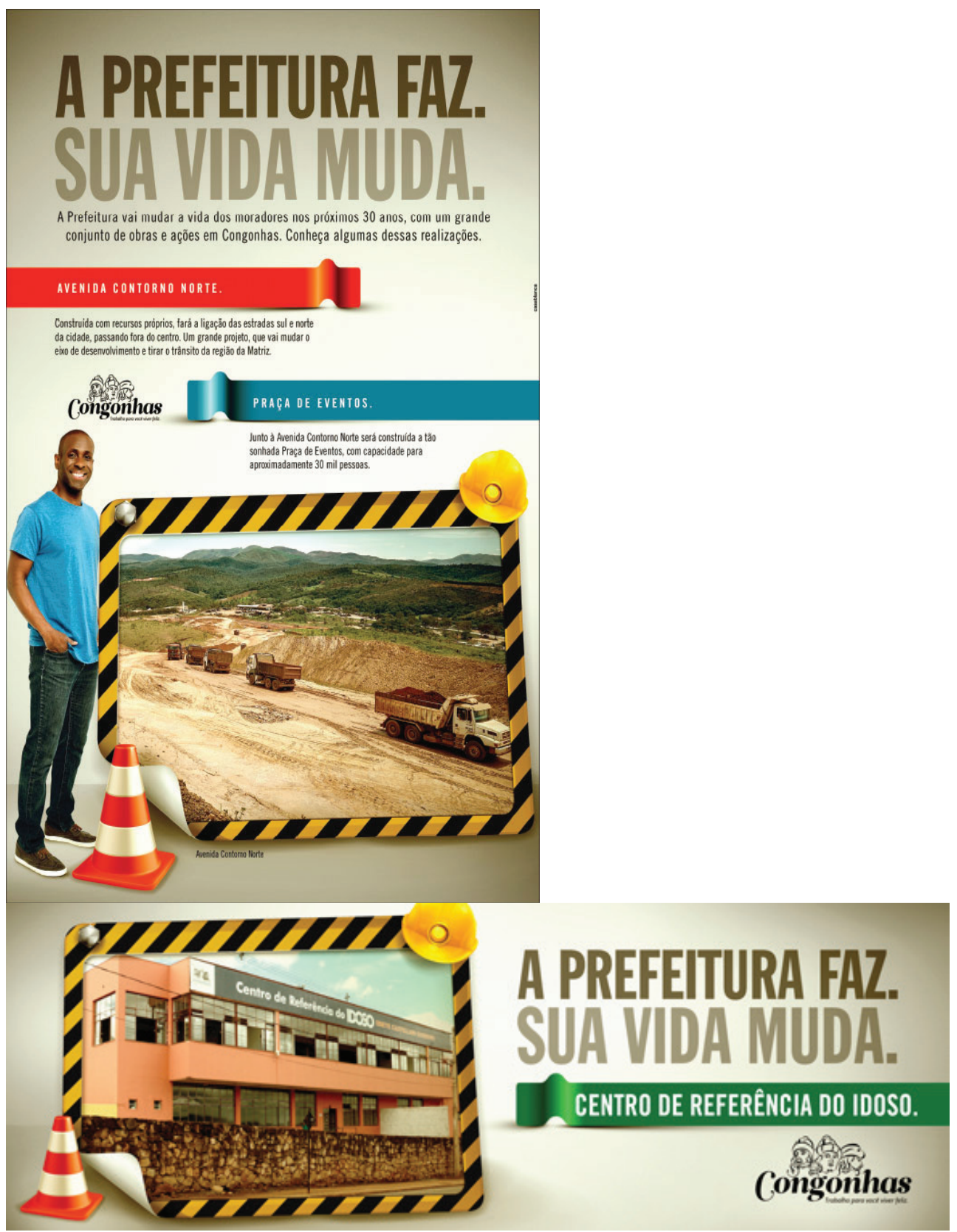


A linguagem verbal e a não verbal têm relação com a abordagem criativa adotada na mensagem. Ao utilizar elementos da vivência do interlocutor, como, por exemplo, no outdoor da cidade de Congonhas, que dá ênfase ao slogan "A Prefeitura faz. Sua vida muda", o publicitário conseguiu uma façanha de marketing, pois segmentou uma mídia de massa. Nessa direção, aproveitou, em cada outdoor, o contexto, utilizando a palavra certa na hora e no local certos,tornando a enunciação extremamente íntima do interlocutor, porque lida com elementos de seu cotidiano.

O mesmo aconteceu em Varginha, também em Minas Gerais:

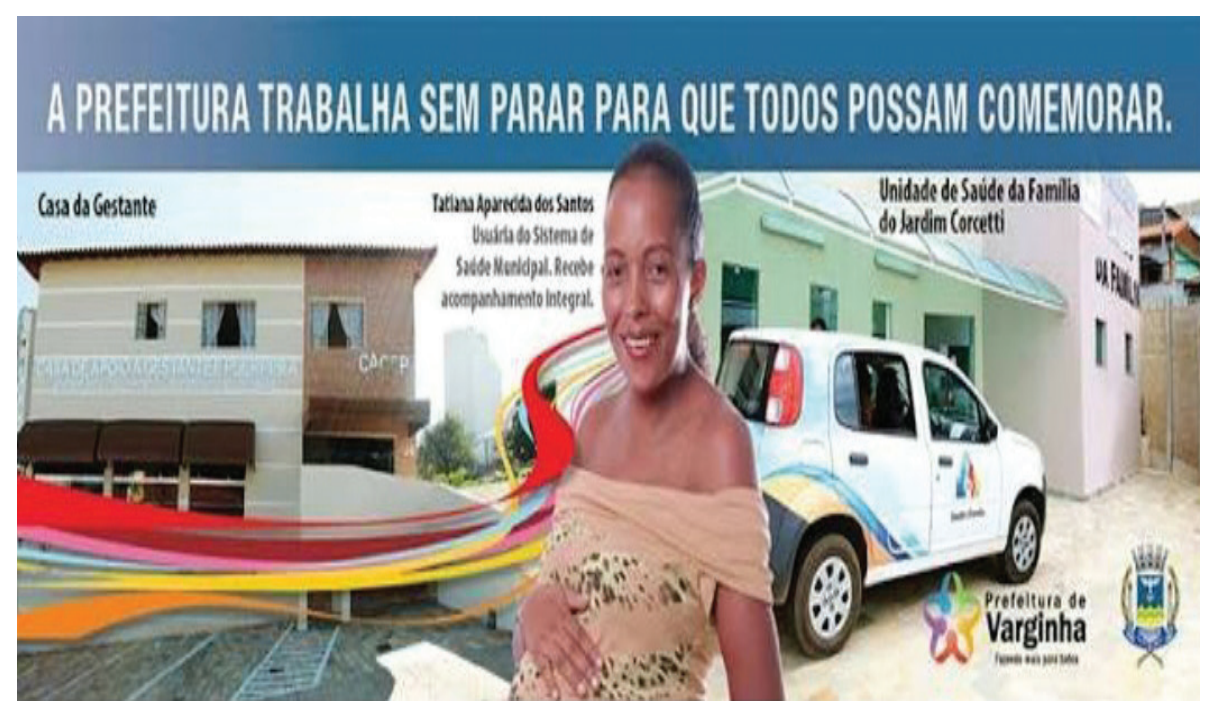

Nos outdoors, o produtor do texto faz uma relação entre a palavra e a localização da placa, ou entre a palavra e o formato da placa. Brinca com as possibilidades desse veículo de comunicação, de tal forma que cada outdoor, se retirado do contexto, perde não só a força argumentativa, como também o sentido da mensagem.

Esse, também, é o caso de Cariacica, no Espírito Santo, que utiliza até a caixa d' água para expor um recado: 


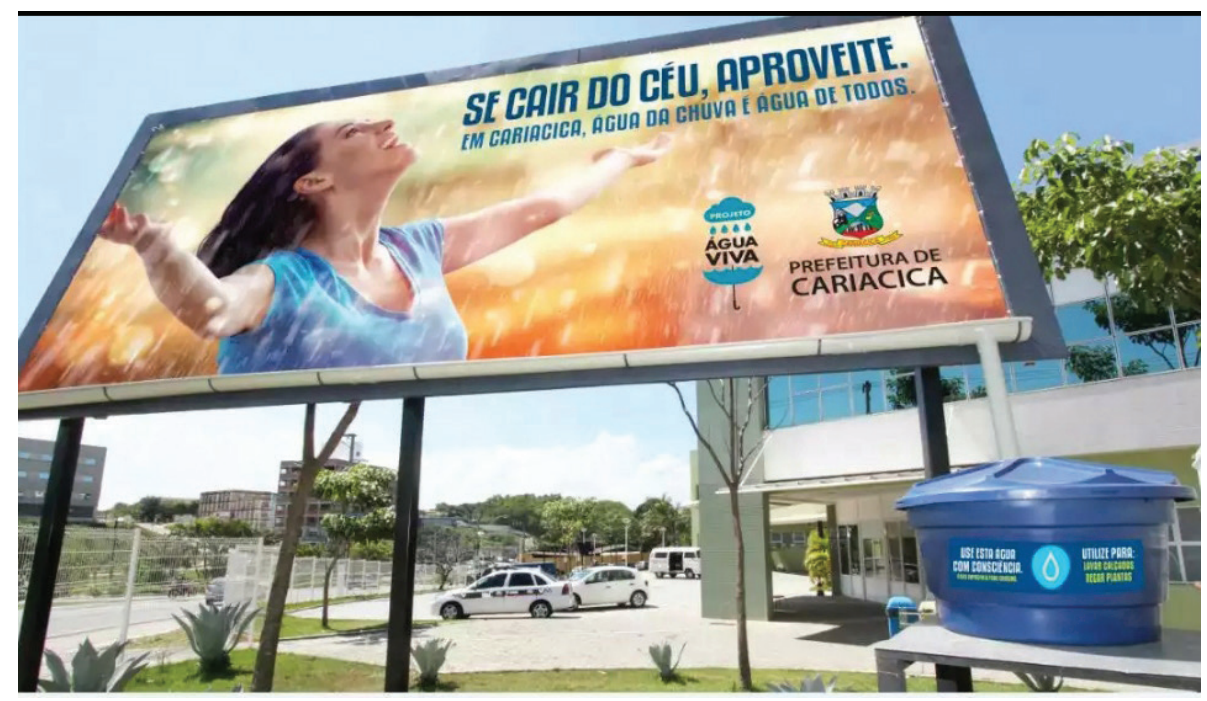

Vejamos a Prefeitura de Atibaia, município do interior de São Paulo:
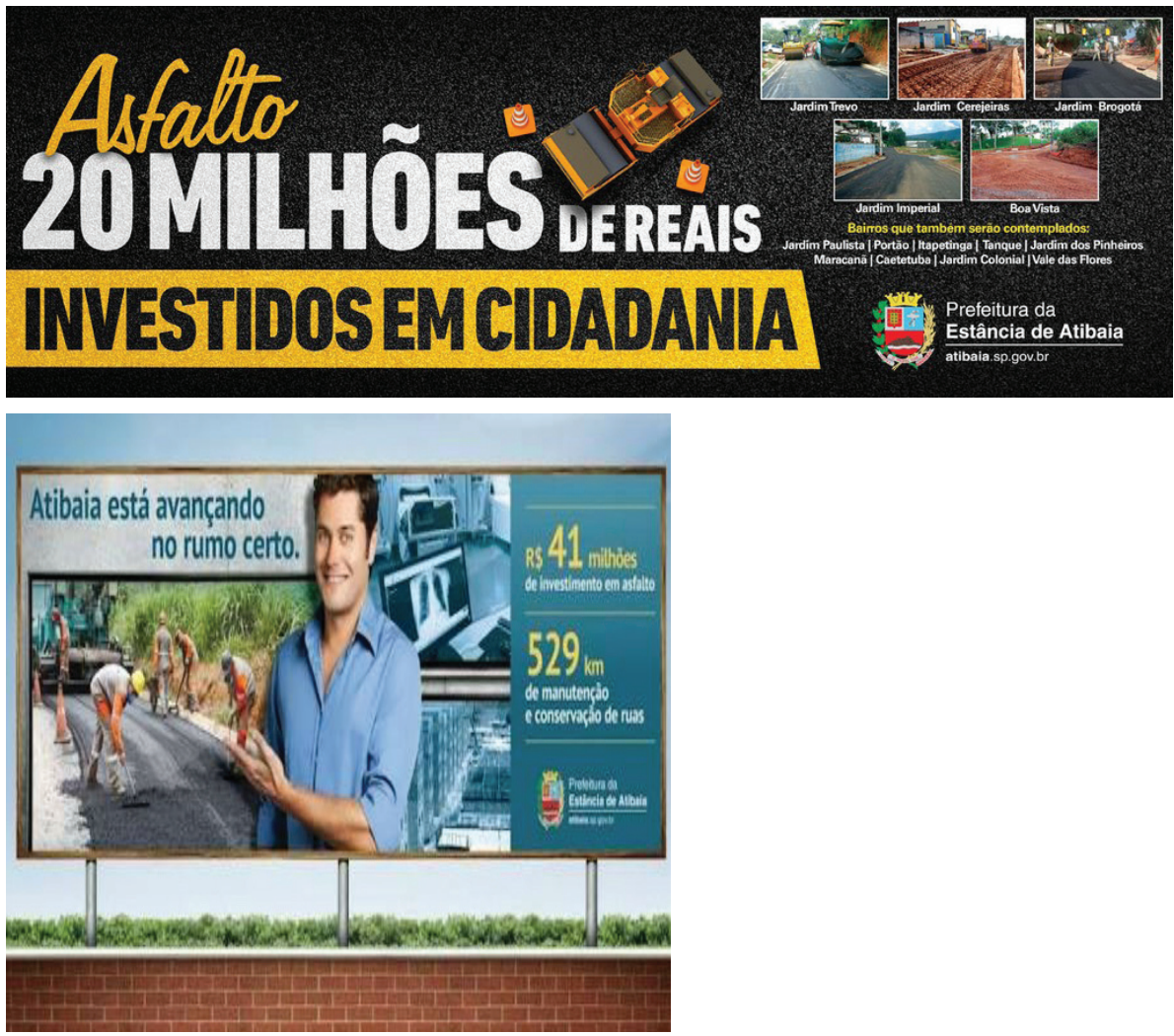
Aqui, temos uma grande contradição, já que, no primeiro outdoor, se divulgou a quantia de 20 milhões de reais investidos em cidadania. Contudo, em todas as imagens aparecem apenas fotos de pavimentação.Sabemos que "cidadania" vai muito além de asfaltar ruas e avenidas. Já no segundo, o valor dobrou. Apenas em asfalto investiram-se 41 milhões de reais. Afinal de contas, quantos milhões esta cidade arrecada? Vale ressaltar que as informações estão totalmente distorcidas e, se a questão de divulgar os valores nas placas é uma forma de prestar contas públicas, então ambas as mensagens dos outdoors não condizem com os próprios anúncios.

Na cidade de Nova Mutum, no Mato Grosso, a situação não é muito diferente:

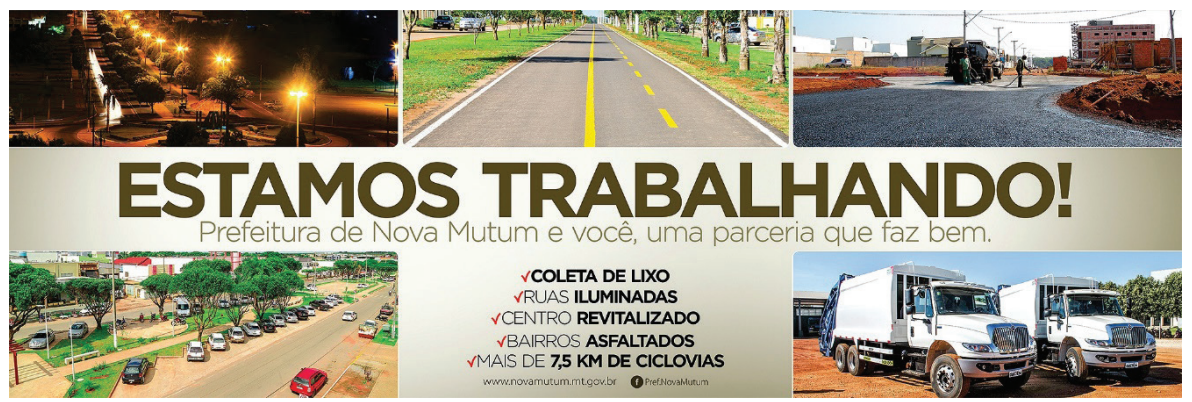

Temos uma Nova Mutum totalmente iluminada, bonita, com ruas limpas, arborizada, em resumo, muito bem estruturada. Faltou trabalhar a questão da educação, da saúde e do saneamento básico.Onde esses quesitos entram? Além disso, a cidade no outdoor,mostra-se harmoniosa. Na prática, é tudo tão perfeito, ou a publicidade constitui apenas uma estratégia para alavancar votos?

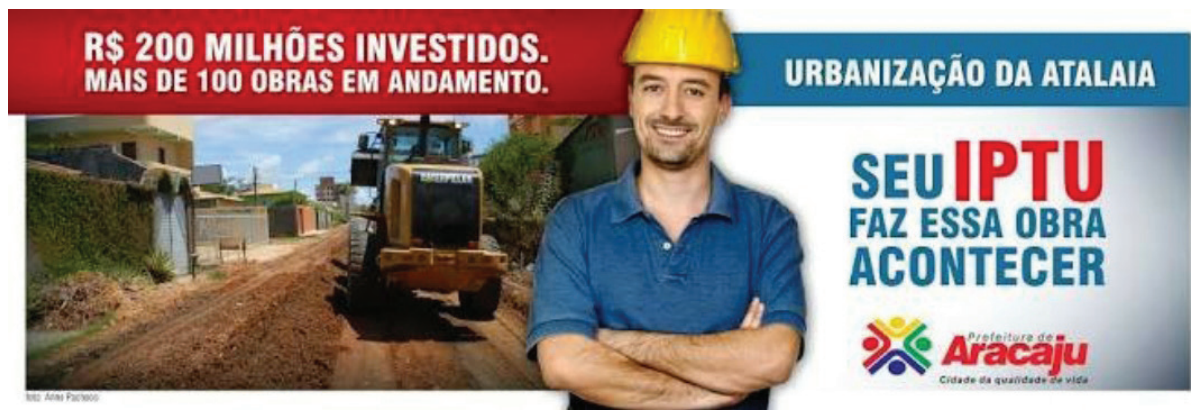

Em Aracaju, o foco para o investimento do IPTU, que girou em torno de 200 milhões de reais, ficou por conta de 100 obras em andamento. Mais quais são as 99 outras obras? No outdoor, detectamos a possível pavimenta- 
ção de uma rua qualquer. Bom, como o outdoor também pode ser utilizado como ferramenta de prestação de contas públicas? Isso não pode acontecer. É extremamente errada a forma como os políticos se apoderam dos outdoors para divulgar o que fazem com o dinheiro público.

Exemplo é o que não falta quando andamos pelas ruas de nossa cidade: os administradores municipais desejam mostrar serviço a qualquer custo, principalmente em anos de eleição, porque a maioria quer ser reeleito, ou eleger algum "amigo" de partido.Por essa razão,todos os dias, a população é bombardeada com uma quantidade enorme de informação e de propaganda.

De acordo com a legislação brasileira, "a propaganda eleitoral somente é permitida após o dia 5 de julho do ano da eleição". Além disso, desde maio de 2006, a Justiça proibiu ouso de outdoors em campanhas.

$\mathrm{Na}$ maioria dos casos, os outdoors têm o objetivo de alavancar pretensões políticas para a eleição seguinte, ainda que os textos não apresentem pedido explícito de voto. Por outro lado, o Tribunal da Justiça Federal entende que, se não ficar claro e visível o pedido de voto, as mensagens devem ser tratadas como promoção pessoal, e não como campanha antecipada. Nesse caso, portanto, não há motivo para punir o político, ou determinar a retirada do painel.

De um modo geral, para os políticos, essa constitui uma maneira de prestar contas à população e divulgar seus trabalhos. Ou seja, não estão cometendo crime algum.

Já na Bahia,encontramos vários exemplos. Porém, analisaremos apenas três cidades.

Vitória da Conquista:

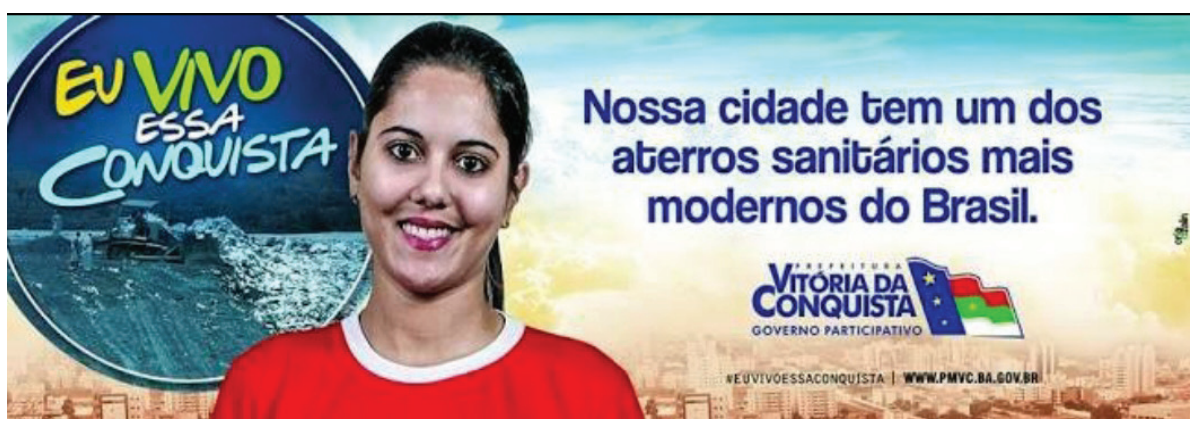

Vitória da Conquista baseou-se em que outras cidades para declarar isso? Como sua propaganda pode afirmar que possuem um dos aterros sanitários mais modernos? A mensagem não está muito vaga? Não constitui maneira errada de persuadir a população? Onde se encontra o fundamento da constatação? São questões como essas que a população da cidade tem de levar em consideração quando se depara com anúncios como este. 


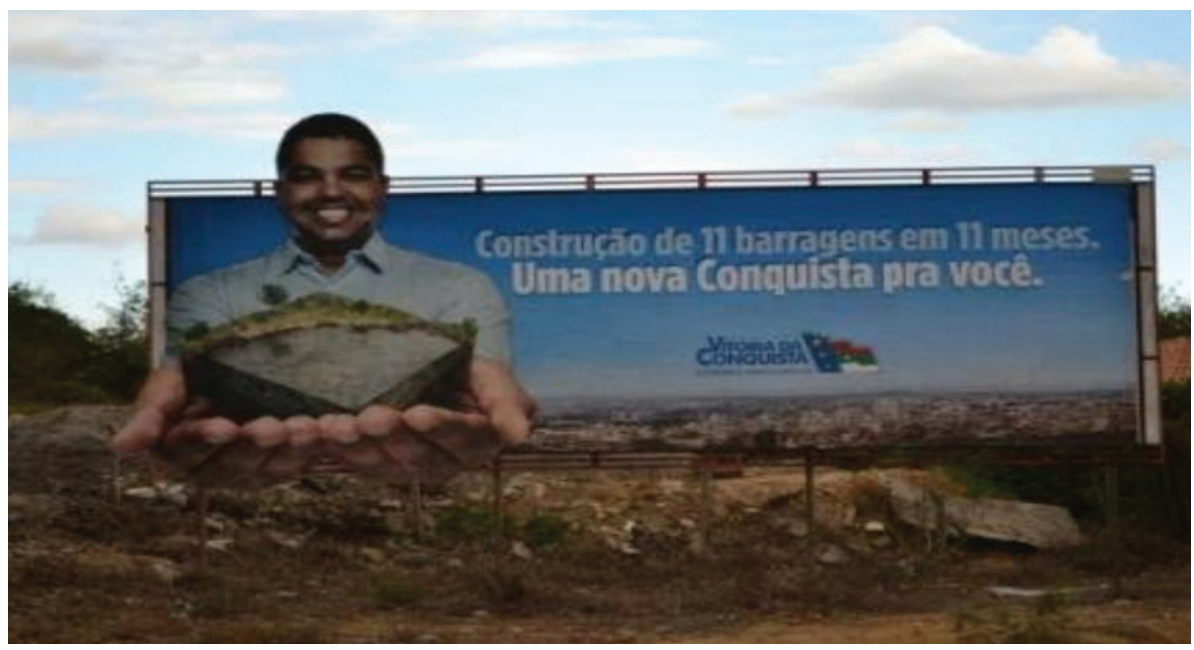

No caso das barragens, aqui até caberia um novo artigo e uma pesquisa mais aprofundada. Os administradores públicos mal conseguem reformar escolas, fornecer material escolar e abastecer postos de saúde. Como conseguiram construir 11 barragens em menos de um ano? Não temos a resposta. Já a cidade de São Sebastião do Passé superou todas as expectativas a esse respeito:

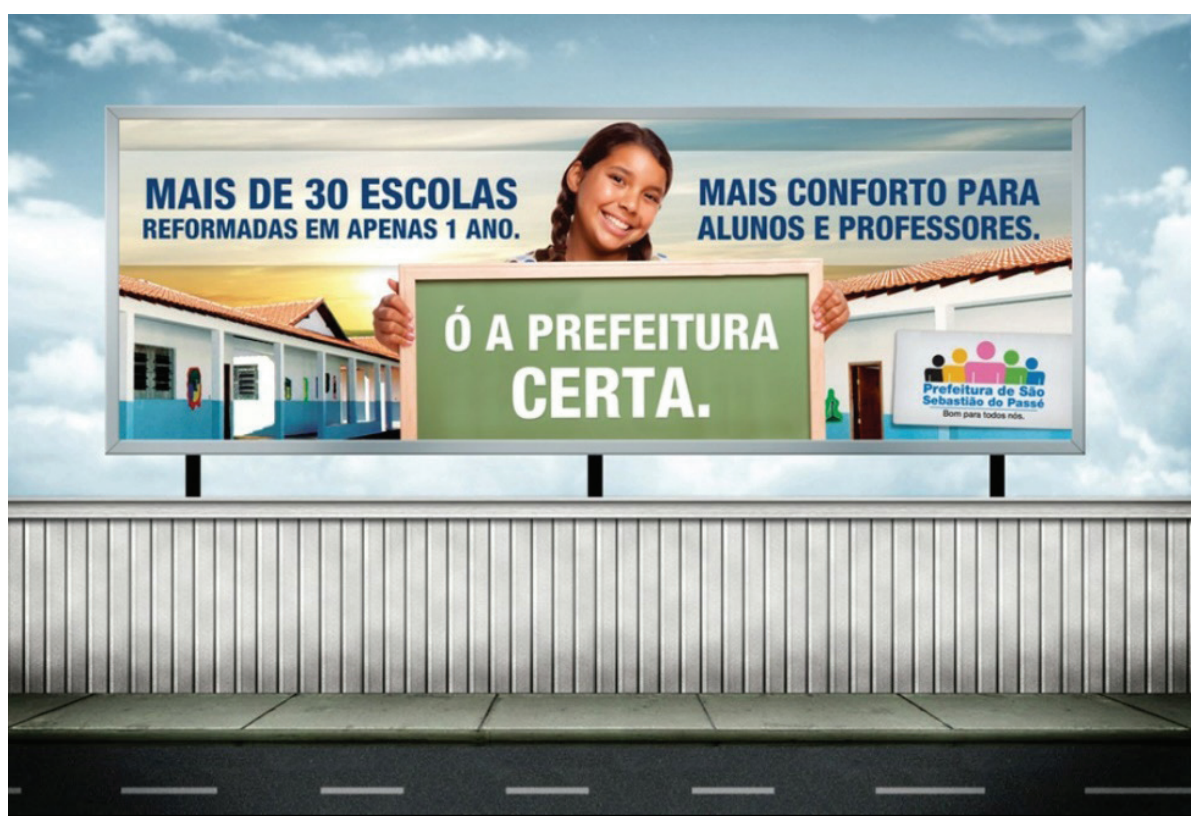


Foram mais, veja bem, mais de 30 escolas reformadas em apenas 1 ano. Isso nos faz pensar, primeiramente, em quanto o município destina de verba para a educação? Qual a renda per capita da cidade? Como foi realizada essa reforma? Afinal, reformar não significa mudar, apenas, as cores das paredes.

Muito clichê: "tá na cara que Mucuri mudou".Se o publicitário queria um cartaz memorável, deveria transmitir uma mensagem com mais eficácia, ou seja, criar cartazes chamativos que se destaquem no ambiente onde estão e que vão ao encontro da realidade da cidade.

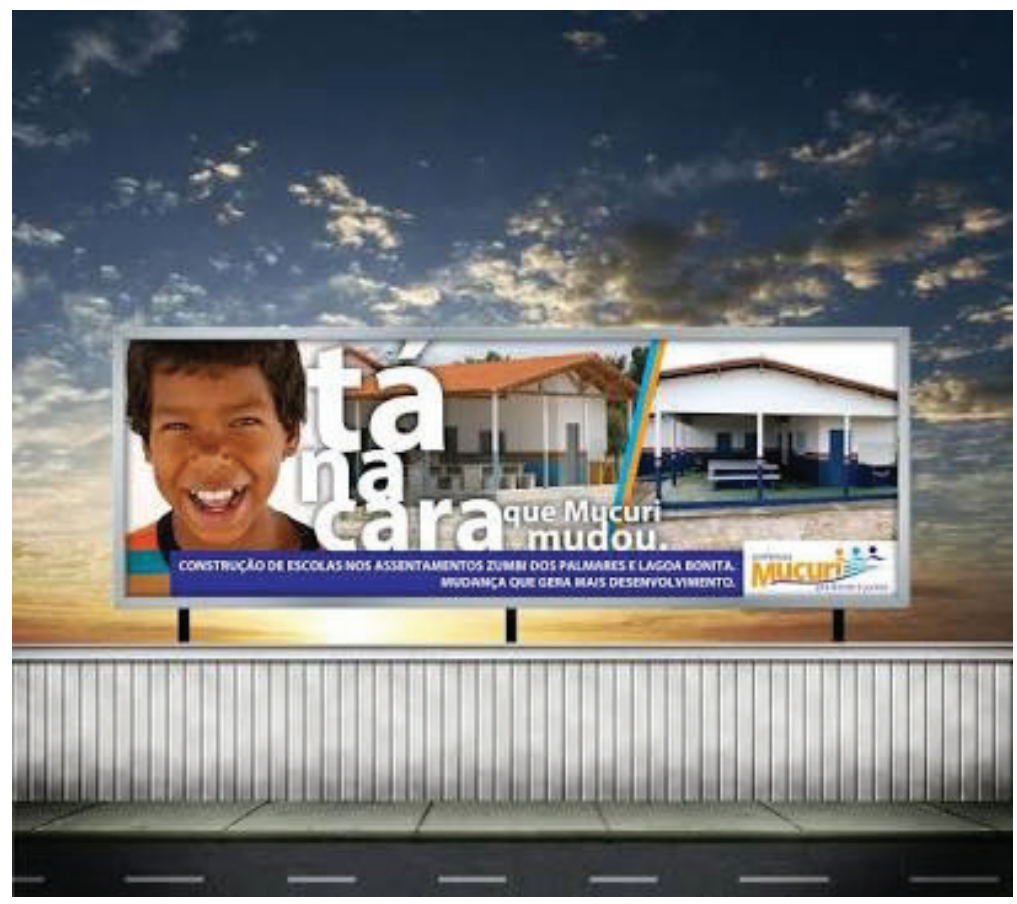

Quais foram as mudanças significativas no município de Mucuri? Apenas a construção de escolas nos assentamentos do Zumbi dos Palmares e da Lagoa Bonita? Quantas escolas foram construídas? As infraestruturas dessas escolas estão adequadas às necessidades dos jovens estudantes?

Contudo educação e saúde constituem necessidades básicas que os governantes devem oferecerá população, além de saneamento básico, para que todos vivam dignamente. Esse tipo de anúncio não deveria ser visto como se o administrador público tivesse realizado algo memorável durante seu mandato. Ao contrário, ele nada fez,além de sua obrigação.

Nessa direção, cabe-nos questionar a recepção e a significação da mensagem político-eleitoral para os cidadãos/eleitores, pois, apesar da afirmação 
de Schwartzenberg (1978) de que esse tipo de mensagem é formatada para ludibriar e manipular o público por meio dos papéis representados pelos candidatos, não nos parece que esses receptores sejam meros títeres nas mãos de marqueteiros e políticos na execução de seus projetos de poder.

Devemos considerar que a política ocupa um papel significativo em nossas mentes, e que dá o tom de nossas significações quanto ao papel ocupado pelos políticos, o que apresenta, a esses atores, a missão de se apropriar ou confrontar essa representação já ancorada (GUARESCHI 2000, p.261).

A comunicação política impacta a sociedade e demanda algum nível de atenção para as mensagens, os discursos e as midiatizações dos papéis representados pelos atores políticos, que desejam conquistar apoio e voto nos momentos de pleito eleitoral. É de suma importância, para entender a comunicação política em sua complexidade de formatação e disseminação ao público-alvo, também pesquisar como esse público perceberá e significará a mensagem a ele direcionada. O eleitor, alvo da comunicação político-eleitoral, recebe-as em um contexto social, o mesmo que o circunda em todas as suas relações cotidianas. Assim, não se podem desconsiderar as possíveis interações e as influências que a relação entre o eleitor, os grupos de pertença e a mensagem político-eleitoral produzirá. Ao longo de sua obra, Serge Moscovici afirma, segundo Campos (2014), que:

Os indivíduos e grupos são os sujeitos que elaboram representações sociais. Deixa claro que elas só existem na interação entre o indivíduo e o grupo, na verdade o grupo é mediador da relação entre o indivíduo e a sociedade; deixa claro que o sujeito é coletivo: de um lado, são representações mentais ou psicológicas porque estão no indivíduo, mas só se mantêm porque esse indivíduo está em um grupo que tem sua experiência na vida social. Assim são representações ao mesmo tempo, psicológicas (no sentido restrito) e sociais. (CAMPOS, 2014, p.1)

E como fica a comunicação em meio a tudo isso? Como deve ser o posicionamento da população diante desses fatos?

Moscovici afirma que "a representação contribui exclusivamente aos processos de formação das condutas e de orientações das comunicações sociais", (MOSCOVICI, 1976, p.75).

Por esse motivo, tornou-se necessário posicionar o produto, ou a marca, num lugar único na mente das pessoas. Carrascoza (1999, p. 18) analisa: 
Hoje, não há dúvida entre os estudiosos da comunicação de que a publicidade é um exemplo notável de discurso persuasivo, com a finalidade de chamar a atenção do público para as qualidades deste ou daquele produto/ serviço, ou de uma marca, em caso de campanhas corporativas. Seu objetivo preclaro não é apenas informar, mas informar e persuadir (1999, p. 18).

PERELMAN (1996) afirma que todo discurso parte de um emissor e se dirige um interlocutor, a quem, mesmo que em níveis diferentes, se visa a convencer e a persuadir. E traça uma clara distinção entre esses verbo: o discurso que pretende convencer é dirigido à razão, ligando-se ao raciocínio lógico e utilizando provas objetivas. Já o discurso que almeja persuadir tem caráter ideológico, subjetivo, liga-se às vontades, aos desejos e aos sentimentos do receptor.

A propaganda política e as campanhas eleitorais, em seu propósito de convencer o leitor a votar em determinado candidato, constituem bons exemplos da arte de vender ideias.O discurso publicitário, por persuasivo, exerce grande poder sobre o público e, na contrapartida, dá poder a quem dele se utiliza. Daí a publicidade desempenhar papel importante em nossa cultura, já que promove a troca simbólica de ideias, de produtos e de serviços.

Marcel Cheida (2003, p.150) considera amplo e complexo o universo da política; além disso, afirma que entender a representação política e a necessidade de intensa comunicação significa compreender os conteúdos que permitem o diálogo entre o político e o eleitor. A comunicação funciona como ferramenta essencial para que esse poder se torne cada vez mais legítimo, pois permite que as intenções e os atos sejam conhecidos do público, do eleitor e do cidadão.

\section{COMUNICAÇA PÚBLICA}

O papel da comunicação pública, no nosso caso municipal, com foco no interesse público, está totalmente desfocado quando se analisam os outdoors em ano eleitoral. Diferente do que se entende por comunicar, as prefeituras visam, claramente, ao voto. Acomunicação pública tem, como objetivos,auxiliar na formação de uma sociedade cidadã e democrática, diminuiras distâncias sociais, reduzir as diferenças eampliar a capacidade analítica individual em prol do coletivo, fato que não constituifavor algum aos munícipes.

Cheida (2003, p. 134) diz que qualquer cidadão pode exigir informações que digam respeito a seus interesses como agente (eleitor) e paciente (cidadão) do processo político. Além disso, a Constituição Federaldelega, à sociedade, uma postura atuante, crítica e responsável. 
A comunicação, processo básico da vida em comunidade, reflete esse novo ambiente e assume características próprias, conceituadas como Comunicação Pública. Cheida (2003, p. 134-135) ressalta que o inciso XIV, do artigo $5^{\circ}$ da Constituição, estabelece que "é assegurado, a todos, o acesso à informação e resguardado o sigilo da fonte, quando necessário ao exercício profissional". Nessa direção, os juristas Celso R. Bastos e Ives G. Martins (1989, p. 80-84 apud CHEIDA, 2003, p. 134-135) ${ }^{1}$ enfatizam que a informação se caracteriza como um bem presenteno processo de reciprocidade entre quem informa e quem é informado:

Durante muito tempo, a luta travada em torno da informação cifrou-se à possibilidade de aquele que possui o conhecimento, a opinião, a crença, transmitir tal cirscuntância aos demais. Não há dúvida de que foi batalha renhida, onde muitos perecem, inclusive na salvaguarda do direito de defenderem pontos de vistas meramente científicos. Quantos então não foram levados à morte por outros crimes de opinião? Mas a liberdade de informar ganhou contornos diferentes nos tempos modernos. Adquiriu-se uma visão integrada do processo informativo, dentro do qual há uma reciprocidade de posições. Aquele que, em dado momento, informa, em outro está a receber informação, da qual, de resto, depende para o próprio desenvolvimento do pensamento (BASTOS e MARTINS, 1989)

Antes de mais nada, há de se esclarecer que o conceito de comunicação pública difere dos de comunicação governamental e de comunicação política. De maneira sucinta, entendemos que a comunicação governamental é praticada pordeterminado governo, visa à prestação de contas, ao engajamento da população nas políticas adotadas e ao reconhecimento das ações promovidas nos campos político, econômico e social. Consiste emuma forma legítima de o governo fazer-se presente junto à população.

A comunicação política, mais conhecida como marketing político, é uma forma de divulgar um político, ou um partido político, focando o processo eleitoral; depende, assim, da insubstituível legitimação da sociedade.

Tanto a comunicação governamental quanto a política têm o objetivo de atingir a opinião pública; na maioria das vezes, fazem uso da propagan$\underline{\text { da }}$, ouda campanha publicitária, em que buscam respostas rápidas e efeitos imediatos por meio de pesquisas de opinião, as quais possam gerar futuras estratégias de campanha. Essa é uma prática muito usual entre os políticos e seus partidos.

BASTOS, Celso R. e MARTINS, Ives G. Comentários à Constituição do Brasil. São Paulo: Saraiva, 1989. p. $80-84$. 
Schwartzenberg (1978) trouxe, em sua obra, uma visão bastante crítica sobre a forma e o uso das comunicações políticas. Afirmando que "a política deixará de ser ideias e se tornará pessoas, ou melhor, personagens" (1978), apresentou-nos a intenção, preponderantemente, maquiavélica que norteia as relações políticas, principalmente as mediadas.

[...] papel representado pelo ator político não é de fato seu reflexo, mas uma idealização deliberada, que enseja encontrar recepção e significação coerentes ao seu objetivo. Relacionando a representação política, no sentido de encenação do papel assumido pelo político em suas relações sociais, com a conquista e a manutenção do poder, o autor nos diz que "o homem político vem procurando cada vez mais impor uma imagem de si mesmo que capte e fixe a atenção do público" (1978, p. 3).

Em um ato de representação, semelhante ao da publicidade, o homem político busca ofuscar defeitos e ressaltar qualidades, independente de possuí-las ou não, oportunas a ostentar. Aparentemente, trata-se de um grande exercício de representação, que cria uma relação simbiótica entre o homem e a imagem que representa. $\mathrm{O}$ autor afirma que:

O homem político deve, portanto, concordar em desempenhar de uma maneira duradoura o personagem em cuja pele se meteu. Precisa aceitar ajustar-se à imagem de si mesmo divulgada pela propaganda. Assim vive ele, aprisionado num emprego determinado,como um ator, e escravo de seu próprio mito (SCHWARTZENBERG,1978, p.6).

GUARESCHI (2000) apresenta a política como uma prática, “e por prática política entendemos uma ação humana intencional que produz relações sociais" (2000, p.263), o que pode nos levar à interpretação de que não se fala de algo estanque quando se fala sobre política, pois,como prática social,não pode ser resumida ou contida em fórmulas herméticas. Sua relação com a sociedade independe de instituições ou de mandatos, intrínseca aos assuntos da própria pólis e de seus habitantes.

Ainda de acordo com o autor, devemos considerar que a política ocupa papel significativo em nossas mentes e dá o tom de nossas significações quanto ao papel ocupado pelos políticos, o que apresenta, a esses atores, a missão de apropriar-se dessa representação já ancorada,ou de confrontá-la.

GUARESCHI (2000) considera a indefinição do tema negativa, ressaltando que: 
[...] nas representações sociais em geral, e na representação social da política em particular, notam-se elementos heterogêneos e até contraditórios. Se a representação social da política possui, por exemplo, características ligadas à manipulação, dominação, sujeira, corrupção etc, ela possui, também, elementos ligados à cidadania, esperança e participação. As representações sociais não são, por conseguinte, unívocas e uniformes (GUARESCHI, 2000, p.269).

Os entusiastas do marketing político,como fomentadores das imagens, podem animar-se ainda mais quando o fato, apontado pelo autor, da falta de uniformidade na representação social da política, deliberada pelos políticos com o intuito de cooptaros cidadãos, encontrar respaldo a suas projeções de imagem.

Ainda recorrendo a Guareschi, o autor vê a política como manipulação e dominação, uma representação que não nos parece positiva e, possivelmente, sirva para afastar os cidadãos/eleitores de assuntos relacionados ao tema:

Temos aqui uma forma indireta de dizer que, se a classe dominante opera uma política de exploração e dominação, é porque o povo o quer assim, porque ele não sabe votar, porque é ignorante,analfabeto etc. [...] Suspeitamos que a partir dessa percepção seja mais fácil compreender a preocupação dos grandes empresários da comunicação em colocar cada vez mais, o tema da política na mídia, apresentando-o como o "oitavo pecado capital”. A mensagem transmitida, neste caso, é que todos os políticos são igualmente corruptos, portanto, não podemos, nem devemos, nos aproximar deles. (GUARESCHI, 2000, p.272)

Porém, nessa direção,os cidadãos devem revisar seu modo de pensar o tema da política. Além disso, faz-se necessário observar o comportamento do cidadão/eleitor frente às novas tecnologias da comunicação, principalmente à internet, por maximizar as trocas de significações e ampliar a quantidade de informações referentes ao assunto.Tais ações visam a proporcionar um novo estágio na forma de comunicar assuntos relacionados à política e às estratégias dos atores políticos.

Segundo Macedo (2007, p. 89), “com a ampliação dos sistemas de comunicação e telecomunicação, os canais de comunicação ampliarão o seu leque de abrangência na transmissão de informação, e com esse crescimento, o poder privado e o poder público vislumbraram essa perspectiva de crescimento na comunicação com seus pares".

Com o avanço do voto eletrônico e das telecomunicações, o eleitor tem desenvolvido cada vez mais o seu senso argumentativo e reflexivo dos can- 
didatos a cargos eletivos. Seu processo decisório na escolha dos postulantes aos cargos eletivos está cada vez mais relacionado a informações que possam circular pelos meios de comunicação impressos e eletrônicos. Por esse motivo, a preocupação de um bom relacionamento com os canais midiáticos é fator estratégico para o fortalecimento e proteção de uma imagem pública de um ator político(MACEDO 2007, p. 89).

Também seguindo um pensamento entusiasta, os pesquisadores equatorianos Jaime Durán Barba e SantiagoNieto contribuem para essa visão ao dizer que:

No solamenteocurre que muchos conceptos que se usaban paraanalizarla política han quedado obsoletos, sino que hay que construirotro modelo de interpretacíon, sinprejuicios, a partir de reconocerque existe unnuevoelector, em una nuevasociedaden que há cambiado todo y la política no puede ser laexcepción (DURÁN BARBA, Jaime y SANTIAGO, Nieto, 2006, p.33).

Talvez possamos começar a reconhecer uma nova maneira de fazer política por meio de ações de comunicação pública,a partir da prática comprometida com a democracia e com a construção da cidadania, o que supõe um posicionamento políticonão partidário.

Segundo Elizabeth Pazito Brandão (2009, p.9), existe uma tendência a identificar a comunicação pública com o viés da comunicação governamental. É interessante notar que a expressão começou a substituir outras denominações utilizadas, tradicionalmente, para designar a comunicação feita pelos governos, tais como comunicação governamental, comunicação política, publicidade governamental e propaganda política.

A expressão comunicação política (CP) vem sendo usada com múltiplos significados, frequentemente conflitantes, dependendo do país, do autor e do contexto em que é utilizada. Tamanha diversidade demonstra que a expressão ainda não é um conceito claro, nem mesmo uma área de atuação profissional delimitada. Pelo menos por enquanto, Comunicação Pública é uma área que abarca uma grande variedade de saberes e atividades e pode-se dizer que é um conceito em processo de construção. (BRANDÃO, 2009, p.09).

A adoção de uma nova terminologia não se dá por acaso, nem é questão de modismo, de buscar novos nomes para práticas já consagradas. Ainda, para Brandão (2009, p. 10), 
[...] a comunicação governamental no Brasil foi, historicamente, de natureza publicitária, isto é, de divulgação de suas ações e utilizou preferencialmente a propaganda com veículação na grande mídia. Diante do novo cenário político no país, a comunicação de origem governamental sofreu transformações e buscou a adoção do sentido de comunicação pública, ou seja, aquela com objetivo de informar o cidadão.

Seguindo essa linha, Duarte (2009, p. 61) diz que a comunicação pública coloca a centralidade do processo no cidadão, não apenas por meio da garantia do direito à informação e à expressão, mas também do diálogo, do respeito a suas características e necessidades e do estímulo à participação ativa, racional e corresponsável. É um bem e um direito de natureza coletiva, envolvendo tudo o que diga respeito a aparato estatal, ações governamentais, partidos políticos, movimentos sociais, empresas públicas, terceiro setor e, até mesmo, em certas circuntâncias, às empresas privadas.

A ideia pode ser julgada ingênua e até utópica, mas Duarte (2009, p. 61) ressalta que o uso da expressão se associa ao esforço de melhorar a vida das pessoas pela comunicação. Para conseguir isso, os instrumentos de comunicação devem ser utilizados sob o ponto de vista do cidadão em sua plenitude,sem reduzi-lo a suas faces de consumidor, eleitor, usuário. Praticar comunicação pública implica assumir espírito público e privilegiar o interesse coletivo, em detrimento de perspectivas pessoais e corporativas.

Nesse contexto, Heloiza Matos (2009, p. 48) lembra um artigo que publicou em 1988, em que estabelece uma diferenciação nos estudos da comunicação governamental:

[...] não estamos tratando das políticas de comunicação como forma de controle e regulamentação ou desregulamentação da propriedade e da utilização dos meios e tecnologias de comunicação. Referimos-nos aqui às normas, princípios e rotinas da comunicação social do governo, explicitadas ou não em suportes legais que visem a regulamentar as comunicações internas e externas do serviço público. [...] consideramos que a comunicação pública envolve também a resposta do cidadão às iniciativas no fluxo das relações comunicativas entre Estado e sociedade.

Sob este prisma, Matos (2009, p. 56) esclarece que comunicação pública é política de inclusão informacional, pois, por meio da comunicação, se diminui o descompasso cognitivo. Produz-se e aloca-se conhecimento, a exemplo do que ocorre no mercado de bens e serviços. Logo, é política pública para a democratização do saber. 
Para Bueno (2009, p. 1),

a comunicação pública está sendo confundida com a propaganda e, o que é pior, não com a propaganda ética, criativa, responsável, mas com personagens do universo da propaganda que afrontam a categoria por sua conduta espúria. Há um tremendo equívoco neste reducionismo e é preciso, de imediato, colocar os pingos nos is. A comunicação pública, que não deve também ser vista como a comunicação do Executivo ou a do Congresso, tem limites menos restritos e exibe inúmeras virtudes. Mais ainda: ela é absolutamente necessária numa democracia.

Bueno (2009, p. 1-2) enfatiza que a comunicação pública transparente e ética, profissionalizada, constitui uma exigência dos tempos modernos porque as autoridades, de qualquer instância, precisam prestar conta de seus atos aos cidadãos.

É sabido que não dispomos ainda de uma cultura de comunicação verdadeiramente disseminada na esfera pública, mas temos avançado bastante. [...] A culpa do equívoco atual, certamente, se origina das próprias autoridades que, sistematicamente, adotam uma visão tacanha da Comunicação Pública e que não hesitam em privilegiar a propaganda (a má propaganda, se confrontados os recursos despendidos e os resultados alcançados nesse esforço) em detrimento de propostas mais abrangentes e mais democráticas.

De acordo com o autor, a comunicação pública tem de pressupor, como foco, a interação com a sociedade, o diálogo e a criação de canais para receber as reivindicações, as demandas, as necessidades e as expectativas dos diferentes segmentos sociais. Não pode "fechar-se em copas", como, parece,tem sido a norma, particularmente em gabinetes refrigerados de Brasília, ou de cidades brasileiras, em que se confunde comunicação pública com "tráfico" de influência.

[...] Não se pode, sob o pretexto de se questionar uma prática mal feita (e bota mal feita nisso em certos escalões da esfera pública brasileira!), negar a importância da comunicação pública. Ela, até por causa dessa bandalheira toda e dessa falta de profissionalismo, é mais necessária do que nunca. Devemos revigorar a comunicação pública, consolidá-la, reforçar o seu perfil positivo, comprometê-la com os verdadeiros anseios do País. [...] A comunicação pública que queremos (e de que precisamos para construir uma democracia verdadeira) deriva da diversidade de ideias, do embate de posições, da defesa intransigente 
da ética, do profissionalismo, do repúdio ao nepotismo e ao uso mesquinho do poder público como forma de consolidar privilégios para grupos e pessoas (BUENO, 2009, p. 2).

Nesse sentido, Bueno (2009, p. 2) finaliza apontando que a comunicação pública não pode ser confundida como esforço de persuasão, já que tem de se afirmar como diálogo permanente e, por isso, não pode resumir-se a campanhas publicitárias, que embutem a promoção de partidos ou de governantes. Pelo contrário, é esse equívoco cometido em nome dela que nos levou a esse impasse e a essa falta de perspectiva.

Todo comunicador que trabalha para propagar informação da esfera pública deveria seguir alguns conceitos bem difundidos por Torquato (2002, p. 122-123:

- a comunicação como base de cidadania: tem a função de atender ao direito à informação. A comunicação deve ser entendida como um dever da comunicação pública e um direito dos usuários e dos consumidores dos serviços. Sonegar tal dever e negar esse direito constitui grave erro das entidades públicas. Os comunicadores precisam internalizar esse conceito, na crença de que a base da cidadania se assenta, também, no direito à informação;

- a comunicação como forma de orientação aos cidadãos: tem função política. Compartilhar as mensagens é democratizar o poder que a comunicação exerce. Assim, detém mais poder quem tem mais informação. Nas estruturas administrativas, tal poder é maior nas altas chefias. E quando se repartem as informações por todos os ambientes e todas as categorias de públicos, o que se está fazendo, de certa forma, é uma repartição de poderes;

- a comunicação como instrumento a serviço da verdade: tem função ética. Não se deve transigir: a verdade deve ser a fonte inspiradora da comunicação pública. Até porque a mentira e as falsas versões acabam desmascaradas. A comunicação precisa servir ao ideário da ética, valor básico dos cidadãos.

\section{CONCLUSÃO}

Constitui ação equivocada usar a comunicação como forma de alavancar votos. É proibido por lei: doar, oferecer, prometer ou entregar qualquer bem ou vantagem pessoal, inclusive emprego ou função pública, com o objetivo de conseguir voto; gastar, em ano eleitoral, em publicidade de órgãos públicos, mais do que a média dos anos anteriores ou mais do que o total do ano 
anterior; na publicidade governamental, haver nomes, fotos ou símbolos de promoção pessoal de autoridade, ou de servidor público.

A campanha eleitoral não está subentendida apenas nos outdoors aqui analisados. As maneiras de convencer o eleitor não têm fim; por isso, as reflexões acerca da conduta política continuam. Será possível a transformação social, sem que se assuma sua dimensão política e sem embates com interesses, privilégios e valores enraizados no capitalismo?

Compreender as relações entre a sociedade e o poder político, bem como as representações sociais, formuladas a partir desse contato, é importante por ser capaz de nos direcionar a uma comunicação mais produtiva para ambos os lados. É angustiante, aos comunicadores e aos políticos, entender que os cidadãos/eleitores não são simples massa de manobra e que não basta apenas "uma grande poluição visual" de mensagens e de imagens pela cidade, sem que se levem em conta as demandas, as perspectivas e as transformações que afetam esse público. Repensar a política em sua relação com o contexto social e os novos eleitores implica repensar a comunicação política.

A partir de nossas análises, acreditamos que, para que haja outdoors mostrando as benfeitorias da cidade, sem haver interesse individual, isto é, apenas repassando informações de forma tranquila, coerente e, acima de tudo,"honesta", novas leis deveriam ser criadas na Constituição Brasileira. O que é pura utopia! Portanto, por tudo que observamos e pesquisamos, concluímos que os administradores públicos usam a publicidade de maneira totalmente incorreta.

Isso porque o papel da comunicação na administração pública deve constituir forma de conhecimento, socialmente partilhado, cujo objetivo prático é construir uma realidade comum a um conjunto social, visando à interação entre a administração pública,local e regional,a sociedade civil e os meios de comunicação.

\section{REFERÊNCIAS}

BRANDÃO, Elizabeth P. Conceitos de Comunicação Pública. IN: DUARTE, Jorge. Comunicação Pública: Estado, mercado, sociedade e interesse público. São Paulo: Atlas, 2009, p. 2-5.

BUENO, Wilson da Costa. Comunicação Empresarial: políticas e estratégias. São Paulo: Saraiva, 2009.

__Em Favor da Verdadeira Comunicação Pública. http://www.fca.pucminas.br/saogabriel/nrp/ em_favor.htm, acessado em 08/08/15.

CARRASCOZA J. A evolução do texto publicitário - A associação de palavras como elemento de sedução na publicidade. São Paulo: Futura, 1999. (1999, p. 18)

CHEIDA, Marcel J. Comunicação Governamental e a Assessoria de Imprensa. Revista de Estudos do Curso de Jornalismo da Pontifícia Universidade Católica de Campinas. São Paulo, Volume 6, nº 01, p. $150,1^{\circ}$ semestre de 2003 . 
DUARTE, Jorge. Comunicação Pública: Estado, mercado, sociedade e interesse público. São Paulo: Atlas, 2009, p.13, 56, 93, 148 e 149.

DURÁN BARBA, Jaime y SANTIAGO, Nieto. Mujer, sexualidade, internet y política: Los nuevoselectoreslatinoamericanos. México: FCE, 2006.

GUARESCHI, Pedrinho A. (org). Os construtores da informação: meios de comunicação, ideologia e ética. Petrópolis: Vozes, 2000.

MACEDO, Roberto Gondo. A importância da assessoria de imprensa no Marketing Político. In: QUEIROZ, Adolpho; MANHANELLI, Carlos; BAREL, Moises (Org.). Marketing Político: do comício a Internet. São Paulo: ABCOP, 2007.

MATOS Heloíza. Comunicação pública, esfera pública e capital social. IN:

MINAYO, M. C. Ciência, técnica e arte: o desafio da Pesquisa Social. In: (Org.) Pesquisa social: teoria, método e criatividade. Petrópolis: Vozes, 2001, p. 09-30.

1994.

O desafio do conhecimento. São Paulo/Rio de Janeiro: HUCITEC-ABRASCO,

MOSCOVICI, S. La psychanalyse son image, son public. Paris: PUF, 1976.

SABADIN, Celso (ORG). Outdoor: uma visão do meio por inteiro. São Paulo: Central do Outdoor, 1990 , p. 29, 83.

SCHWARTZENBERG, Roger-Gérard. O Estado Espetáculo. Tradução Heloysa de Lima Dantas. São Paulo: Difel Difusão Editora S.A., 1978.

STUMPF, C. Regina Ida.Métodos e técnicas de pesquisa em comunicação. Pesquisa bibliográfica. IN: DUARTE, Jorge. (Org). 2 2a ed. São Paulo: Atlas, 2009, p.52,54.

TORQUATO, Gaudêncio. Tratado de Comunicação Organizacional e Política. São Paulo: Thomson, 2002, p.81, 83, 84, 87 . 